\title{
Secondary and cumulative meta-analysis of olanzapine for antiemetic prophylaxis for chemotherapy-induced nausea and vomiting: do we still need to study its effectiveness?
}

\author{
Leonard Chiu ${ }^{1,2}$, Ronald Chow ${ }^{2,3,4}$, Carlo DeAngelis ${ }^{2,5}$, Michael Lock ${ }^{3}$, Charles B. Simone II ${ }^{6}$ \\ ${ }^{1}$ Columbia University Vagelos College of Physicians and Surgeons, New York, NY, USA; ${ }^{2}$ Sunnybrook Odette Cancer Centre, University of Toronto, \\ Toronto, ON, Canada; ${ }^{3}$ London Regional Cancer Program, University of Western Ontario, London, ON, Canada; ${ }^{4}$ Yale School of Public Health, \\ Yale University, New Haven, CT, USA; ${ }^{5}$ Leslie Dan Faculty of Pharmacy, University of Toronto, Toronto, ON, Canada; ${ }^{6}$ New York Proton Center, \\ New York, NY, USA \\ Contributions: (I) Conception and design: L Chiu, R Chow; (II) Administrative support: All authors; (III) Provision of study materials or patients: \\ L Chiu, R Chow; (IV) Collection and assembly of data: L Chiu, R Chow; (V) Data analysis and interpretation: L Chiu, R Chow; (VI) Manuscript \\ writing: All authors; (VII) Final approval of manuscript: All authors. \\ Correspondence to: Dr. Charles B. Simone II, MD. Professor and Chief Medical Officer, New York Proton Center, Member, Memorial Sloan Kettering \\ Cancer Center, New York, NY, USA. Email: csimone@nyproton.com.
}

Background: Olanzapine has been found to have antiemetic properties due to its ability to inhibit multiple serotonergic, dopaminergic, alpha-1 adrenergic and histamine receptors. In 2016, a meta-analysis of 10 randomized controlled trials (RCTs) on olanzapine in the prophylactic setting found olanzapine to be more efficacious than other standard antiemetics in the prophylactic setting. However, since the review, many clinical trials using olanzapine for chemotherapy-induced nausea and vomiting (CINV) have been published-in many cases, contending that further trials would further help elucidate the efficacy of olanzapine for CINV given the continued paucity of literature. The primary aim of this study is to conduct a secondary, cumulative meta-analysis to assess the impact of the most recent trials on the published effect estimate of olanzapine and ultimately determine whether trials published since 2016 have significantly changed the summary estimate.

Methods: As reported previously, a literature search was conducted up until 2015, of Ovid Medline, Embase and the Cochrane Central Register of Controlled Trials; 10 RCTs with a total of over 1,000 patients were included, that compared olanzapine to other antiemetics in the prophylactic setting, which reported on at least one of two endpoints—no emesis and no nausea. The Mantel-Haenszel, random-effects analysis model was used to compute cumulative risk ratios (RR) and their accompanying $95 \%$ confidence intervals (CIs).

Results: For the endpoint of emetic control, the cumulative meta-analysis shows that the summary effect did not change noticeably with the inclusion of the most recent trials. In the acute phase, the RR shifted from 1.07 before 2011 to 1.10 after 2015, even after the inclusion of 7 trials. Similar small changes were noted in the delayed and overall phases. For the endpoint of nausea control, the cumulative meta-analysis does show a significant visual change in summary effect, except for nausea control in the acute phase. In the delayed phase, the RR shifts from 1.58 before 2011 to 1.50 after 2015. In the overall phase, the RR shifts from 1.642 before 2011 to 1.53 after 2015 .

Conclusions: Olanzapine's efficacy for the prophylaxis of CINV has been sufficiently documented, with respect to emetic control. There is, however, more limited data supporting its efficacy with respect to nausea control.

Keywords: Olanzapine; prophylaxis; chemotherapy-induced nausea and vomiting; meta-analysis; antiemetic 
Submitted Jul 22, 2020. Accepted for publication Dec 02, 2020.

doi: 10.21037/apm-20-1462

View this article at: http://dx.doi.org/10.21037/apm-20-1462

\section{Introduction}

Chemotherapy-induced nausea and vomiting (CINV) is a common and burdensome adverse effect for cancer patients receiving chemotherapy treatment (1). Patients frequently report a lower quality of life and may present with clinical conditions of dehydration, malnutrition and treatment nonresponse (2). These debilitating side effects may ultimately lead to decreased chemotherapy dose administration and poor patient adherence, both compromising management for patients on chemotherapy.

Antiemetics have been studied and developed to target specific pathways that are postulated to be involved in CINV. Neurokinin-1 receptor antagonists such as aprepitant, rolapitant and netupitant, are prescribed to block substance $P$, which initiates impulses to the emesis center in the medulla (3-5). 5-hydroxytryptamine type 3 (5$\mathrm{HT}_{3}$ ) receptor antagonists such as ondansetron, granisetron and palonosetron, are administered to interrupt the pathway where serotonin from enterochromaffin cells bind to $5-\mathrm{HT}_{3}$ receptors $(6,7)$.

Over the past decade, olanzapine has been used in the antiemetic setting. Originally approved by the Food and Drug Administration to treat psychosis, it was speculated that olanzapine may be an effective antiemetic due to its ability to inhibit multiple serotonergic, dopaminergic, alpha-1 adrenergic and histamine receptors (8). A review of phase I and II trials by Chow et al. reported good efficacy of olanzapine (9). A meta-analysis of phase III trials by Chiu et al. in 2016 reported that olanzapine is more efficacious than other standard antiemetics in the prophylactic setting (10). Since then, international clinical guidelines by the American Society of Clinical Oncology (ASCO) (11) and National Comprehensive Cancer Network (NCCN) (12) have subsequently recommended olanzapine to be added as the fourth drug in a standard prophylactic CINV regimen, citing these aforementioned reviews.

However, since the 2016 review, many clinical trials using olanzapine for CINV have been started, completed, and published-in many cases, citing the paucity of literature at the time as support for initiating their trial and the need for further research in this setting (13-15).
It remains to be seen whether there was indeed a paucity of data on the use of olanzapine for the CINV setting in 2016. Indeed, if there were already sufficient evidence for the use of olanzapine in 2016, one would expect the most recent clinical trials to have little effect on the summary estimate in a meta-analysis; that is to say, the existing body of literature would have encompassed such a large sample of patients such that the results of additional trials would only shift the effect size minimally and unremarkably (16).

The primary aim of this study is to conduct a secondary cumulative meta-analysis to provide insight into the effect of the most recent trials on the published effect estimate of olanzapine as an anti-nausea and anti-emesis agent, and to determine whether the trials published since 2016 have significantly changed the summary estimate.

\section{Methods}

\section{Included studies and data}

As specified a priori (Appendix 1), all papers and data reporting on olanzapine for the prophylaxis of CINV included by Chiu et al. (10) were included in this secondary meta-analysis. As reported previously, a literature search was conducted up until 2015, of Ovid Medline, Embase and the Cochrane Central Register of Controlled Trials; 10 randomized controlled trials (RCTs) with a total of over 1,000 patients (17-26) were included, that compared olanzapine to other antiemetics in the prophylactic setting, which reported on at least one of two endpointsno emesis and no nausea. Two endpoints of emesis and nausea were included in this analysis, analyzed separately by time of incidence of CINV-acute ( 0 up to 24 hours post-chemotherapy), delayed (beyond 24 up to 120 hours post-chemotherapy) and overall phases (0-120 hours postchemotherapy). Data was collected in duplicate by two authors (LC, RC).

\section{Statistical analysis}

The Mantel-Haenszel, random-effects analysis model was used to compute cumulative risk ratios (RR) and their 
accompanying $95 \%$ confidence intervals (CIs). All analyses were conducted using Comprehensive Meta-Analysis (Version 3), by BioStat (AnalystSoft Inc., Alexandria, VA, USA). Funnel plots were also generated, to visually assess for publication bias.

We present the following article in accordance with the PRISMA reporting checklist (available at http://dx.doi. org/10.21037/apm-20-1462.

\section{Results}

\section{Cumulative meta-analysis: emesis and nausea}

For the endpoint of emetic control, the cumulative metaanalysis shows that the summary effect did not change noticeably with the inclusion of the most recent trials. In the acute phase, the RR shifted from 1.07 before 2011 to 1.10 after 2015, even after the inclusion of 7 trials. Similar small changes were noted in the delayed phase, with the RR shifting from 1.23 before 2011 to 1.40 after 2015 and the overall phase, with RR shifting from 1.22 before 2011 to 1.53 after 2015. As expected, the CI did narrow with the inclusion of the most recent trials in all phases (Figure 1).

For the endpoint of nausea control, the cumulative metaanalysis does show a significant visual change in summary effect, except for nausea control in the acute phase. In the delayed phase, the RR shifts from 1.58 before 2011 to 1.50 after 2015. In the overall phase, the RR shifts from 1.642 before 2011 to 1.53 after 2015 . The CI in the acute phase is narrow relative to the summary estimates for the delayed and overall phases (Figure 2).

\section{Assessment for publication bias}

There were no remarkable concerns for publication bias, based on visual assessment of the generated funnel plots (Figures 3,4).

\section{Rescue of breakthrough CINV}

There were only three studies reporting on the efficacy of olanzapine in the rescue of breakthrough CINV. The summary estimate effect did change over time, and olanzapine remains significantly superior to other compared interventions (Figure S1). For this analysis, assessment for publication bias via funnel plot similarly did not lead to any concerns of bias, but the paucity of data does not lead to a definitive conclusion (Figure S2).

\section{Discussion}

The purpose of this paper was to appraise the review by Chiu et al. to see the impact of the most-recent publications on the meta-analysis. A cumulative meta-analysis is a sequence of meta-analyses performed on a subset of studies, starting with a single study and adding the other studies one at a time. In this way, we can assess the effect of the last few trials included in the Chiu $e t a l$. review and see how each study affects the meta-analysis' point estimate and CI. A lack of significant change with the addition of the last couple trials suggests that the published literature had already generated a precise treatment effect-supporting the conclusion that further trials assessing olanzapine for CINV are unnecessary.

In this cumulative analysis, the summary effect size seems to be well-established for the endpoint of emetic control, as the summary effect did not change appreciably with the inclusion of the most recent trials. The same cannot be said for nausea control for the delayed and overall phasesthe summary estimate did change noticeably. These observations are accompanied by wide CIs, supporting the view that there remains a paucity of data reported in the literature on nausea control.

The lack of publication bias seen in this analysis confirms that the existing published literature provides an accurate report and assessment of olanzapine's efficacy. The lack of publication bias found in this study indicates that there is not an oversaturation of studies that over- or understate olanzapine's efficacy. When interpreted alongside the minimal change in effect size for the endpoint of emetic control, there is minimal support from this analysis for studies since 2016 that solely report on emetic control. However, given the paucity of data for nausea control, it may be appropriate to assess both endpoints in recent trials. In the interest of efficiently allocating scarce trial resources, studies solely reporting emetic control may not have been necessary.

This study is not without limitations. As it is a metaanalysis, it is subject to the same constraints and biases inherent in the design of the individual RCTs. Furthermore, the use of funnel plots to visually assess for publication bias is not as robust as a quantitative statistical test such as Egger's test. But, the lack of obvious visual evidence of bias mitigated the need to employ Egger's test.

In conclusion, olanzapine's efficacy for the prophylaxis 
Acute Phase

Study name

$\begin{array}{lcrrrr} & \text { Point } & \begin{array}{r}\text { Lower } \\ \text { limit }\end{array} & \begin{array}{r}\text { Upper } \\ \text { limit }\end{array} & \text { Z-Value } & \text { p-Value } \\ \text { Shumway et al, 2009 } & 1.688 & 0.727 & 3.917 & 1.218 & 0.223 \\ \text { Tan et al, 2009 } & 1.022 & 0.889 & 1.174 & 0.303 & 0.762 \\ \text { Mao et al, 2011 } & 1.077 & 0.963 & 1.204 & 1.302 & 0.193 \\ \text { Navari et al, 2011 } & 1.091 & 0.998 & 1.192 & 1.924 & 0.054 \\ \text { Wang et al, 2012 } & 1.111 & 1.019 & 1.211 & 2.394 & 0.017 \\ \text { Mizukami et al, 2014 } & 1.116 & 1.030 & 1.210 & 2.690 & 0.007 \\ \text { Mukhopadhyay et al, 2015 } & 1.099 & 1.024 & 1.179 & 2.628 & 0.009 \\ \text { Navari et al, 2015 } & 1.094 & 1.024 & 1.169 & 2.651 & 0.008 \\ \text { Wang et al, 2015 } & 1.099 & 1.031 & 1.171 & 2.894 & 0.004 \\ & 1.099 & 1.031 & 1.171 & 2.894 & 0.004\end{array}$

Cumulative $\mathrm{mh}$ risk ratio $(95 \% \mathrm{Cl})$

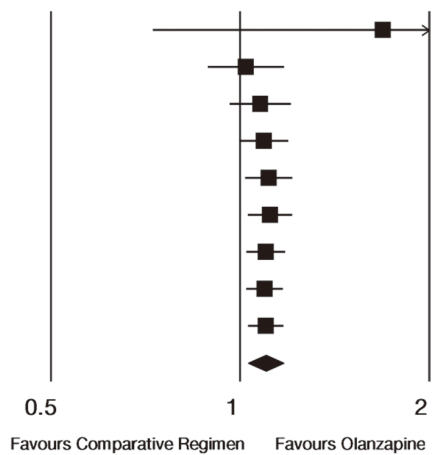

Delayed Phase

Study name

$\begin{array}{lcrrrr} & \text { Point } & \begin{array}{r}\text { Lower } \\ \text { limit }\end{array} & \begin{array}{r}\text { Upper } \\ \text { limit }\end{array} & \text { Z-Value } & \text { p-Value } \\ \text { Shumway et al, 2009 } & 1.125 & 0.473 & 2.674 & 0.267 & 0.790 \\ \text { Tan et al, 2009 } & 1.227 & 0.868 & 1.735 & 1.156 & 0.248 \\ \text { Mao et al, 2011 } & 1.376 & 1.042 & 1.817 & 2.247 & 0.025 \\ \text { Navari et al, 2011 } & 1.249 & 0.999 & 1.563 & 1.952 & 0.051 \\ \text { Wang et al, 2012 } & 1.286 & 1.053 & 1.570 & 2.468 & 0.014 \\ \text { Mizukami et al, 2014 } & 1.299 & 1.083 & 1.557 & 2.825 & 0.005 \\ \text { Mukhopadhyay et al, 2015 } & 1.394 & 1.177 & 1.652 & 3.841 & 0.000 \\ \text { Navari et al, 2015 } & 1.337 & 1.143 & 1.564 & 3.626 & 0.000 \\ \text { Wang et al, 2015 } & 1.313 & 1.135 & 1.518 & 3.671 & 0.000 \\ & 1.313 & 1.135 & 1.518 & 3.671 & 0.000\end{array}$

Overall Phase

Study name

$\begin{array}{lrrrrr} & \text { Point } & \begin{array}{r}\text { Lower } \\ \text { limit }\end{array} & \begin{array}{r}\text { Upper } \\ \text { limit }\end{array} & \text { Z-Value } & \text { p-Value } \\ \text { Shumway et al, 2009 } & 1.125 & 0.449 & 2.818 & 0.251 & 0.802 \\ \text { Tan et al, 2009 } & 1.219 & 0.793 & 1.874 & 0.904 & 0.366 \\ \text { Mao et al, 2011 } & 1.534 & 1.074 & 2.190 & 2.355 & 0.019 \\ \text { Navari et al, 2011 } & 1.342 & 1.007 & 1.789 & 2.010 & 0.044 \\ \text { Wang et al, 2012 } & 1.369 & 1.060 & 1.769 & 2.404 & 0.016 \\ \text { Lu et al, 2013 } & 1.433 & 1.127 & 1.823 & 2.933 & 0.003 \\ \text { Mizukami et al, 2014 } & 1.436 & 1.152 & 1.790 & 3.223 & 0.001 \\ \text { Mukhopadhyay et al, 2015 } & 1.528 & 1.244 & 1.877 & 4.044 & 0.000 \\ \text { Navari et al, 2015 } & 1.450 & 1.198 & 1.755 & 3.812 & 0.000 \\ \text { Wang et al, 2015 } & 1.408 & 1.178 & 1.683 & 3.758 & 0.000 \\ & 1.408 & 1.178 & 1.683 & 3.758 & 0.000\end{array}$

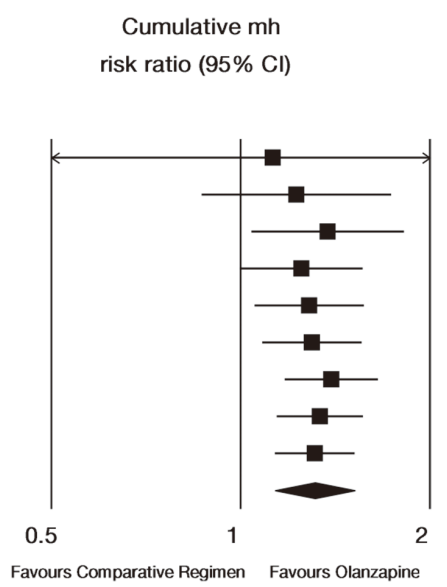

Favours Comparative Regimen Favours Olanzapine
Cumulative mh risk ratio $(95 \% \mathrm{Cl})$

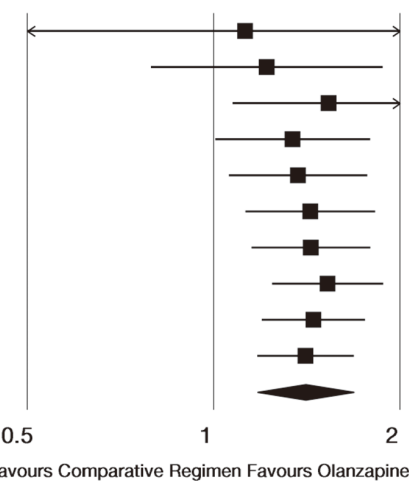

Favours Comparative Regimen Favours Olanzapine

Figure 1 Cumulative efficacy of olanzapine for the prophylaxis of chemotherapy-induced emesis. 
Acute Phase

Study name

\begin{tabular}{|c|c|c|c|c|c|}
\hline \multirow{3}{*}{ Study name } & \multirow[b]{3}{*}{ Point } & \multicolumn{4}{|c|}{ Acute Phase } \\
\hline & & \multicolumn{4}{|c|}{ Cumulative statistics } \\
\hline & & $\begin{array}{c}\text { Lower } \\
\text { limit }\end{array}$ & $\begin{array}{c}\text { Upper } \\
\text { limit }\end{array}$ & Z-Value & p-Value \\
\hline Shumway et al, 2009 & 0.675 & 0.232 & 1.965 & -0.721 & 0.471 \\
\hline Tan et al, 2009 & 1.064 & 0.993 & 1.139 & 1.764 & 0.078 \\
\hline Navari et al, 2011 & 1.043 & 0.986 & 1.103 & 1.464 & 0.143 \\
\hline Wang et al, 2012 & 1.046 & 0.991 & 1.105 & 1.624 & 0.104 \\
\hline \multirow[t]{2}{*}{ Navari et al, 2015} & 1.051 & 0.998 & 1.108 & 1.874 & 0.061 \\
\hline & 1.051 & 0.998 & 1.108 & 1.874 & 0.061 \\
\hline
\end{tabular}

Study name

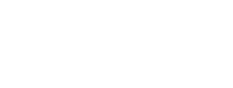

Shumway et al, 2009

Tan et al, 2009

Navari et al, 2011

Wang et al, 2012

Navari et al, 2015

Cumulative statistics

$\begin{array}{crrrr}\text { Point } & \begin{array}{r}\text { Lower } \\ \text { limit }\end{array} & \begin{array}{r}\text { Upper } \\ \text { limit }\end{array} & \text { Z-Value } & \text { p-Value } \\ 1.125 & 0.285 & 4.446 & 0.168 & 0.867 \\ 1.578 & 0.959 & 2.595 & 1.795 & 0.073 \\ 1.679 & 1.162 & 2.427 & 2.758 & 0.006 \\ 1.453 & 1.076 & 1.962 & 2.436 & 0.015 \\ 1.502 & 1.147 & 1.968 & 2.954 & 0.003 \\ 1.502 & 1.147 & 1.968 & 2.954 & 0.003\end{array}$

Overall Phase

Study name

\begin{tabular}{|c|c|c|c|c|c|}
\hline & Point & $\begin{array}{c}\text { Lower } \\
\text { limit }\end{array}$ & $\begin{array}{c}\text { Upper } \\
\text { limit }\end{array}$ & Z-Value & p-Value \\
\hline Shumway et al, 2009 & 1.125 & 0.288 & 4.392 & 0.170 & 0.865 \\
\hline Tan et al, 2009 & 1.642 & 1.023 & 2.636 & 2.053 & 0.040 \\
\hline Navari et al, 2011 & 1.717 & 1.211 & 2.434 & 3.037 & 0.002 \\
\hline Wang et al, 2012 & 1.481 & 1.113 & 1.970 & 2.693 & 0.007 \\
\hline \multirow[t]{2}{*}{ Navari et al, 2015} & 1.525 & 1.180 & 1.972 & 3.220 & 0.001 \\
\hline & 1.525 & 1.180 & 1.972 & 3.220 & 0.001 \\
\hline
\end{tabular}

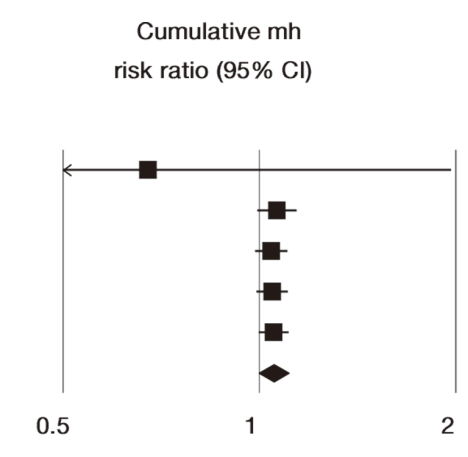

Favours Comparative Regimen Favours Olanzapine

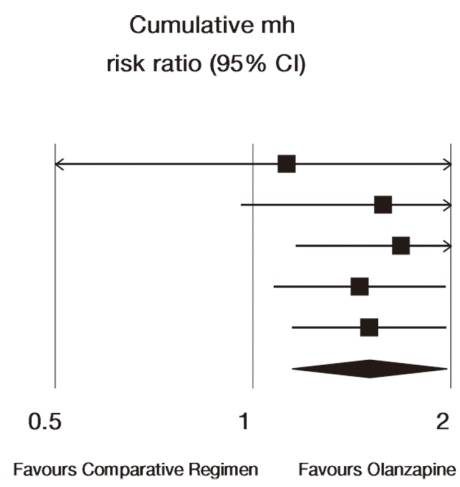

Favours Comparative Regimen Favours Olanzapine

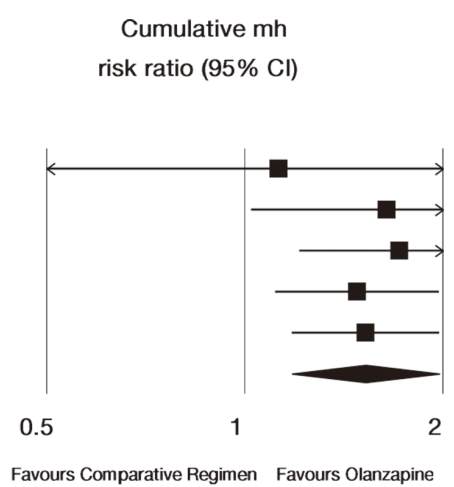

Figure 2 Cumulative efficacy of olanzapine for the prophylaxis of chemotherapy-induced nausea.

of CINV has been sufficiently documented with respect to emetic control. There is, however, a paucity of data with respect to nausea control. As an aside, there is also a paucity of data documenting the efficacy of olanzapine for the rescue of breakthrough CINV. To better allocate trial resources, further studies studying olanzapine for CINV in terms of emetic control may be unnecessary, whereas future studies should focus efforts on better documenting nausea control. 

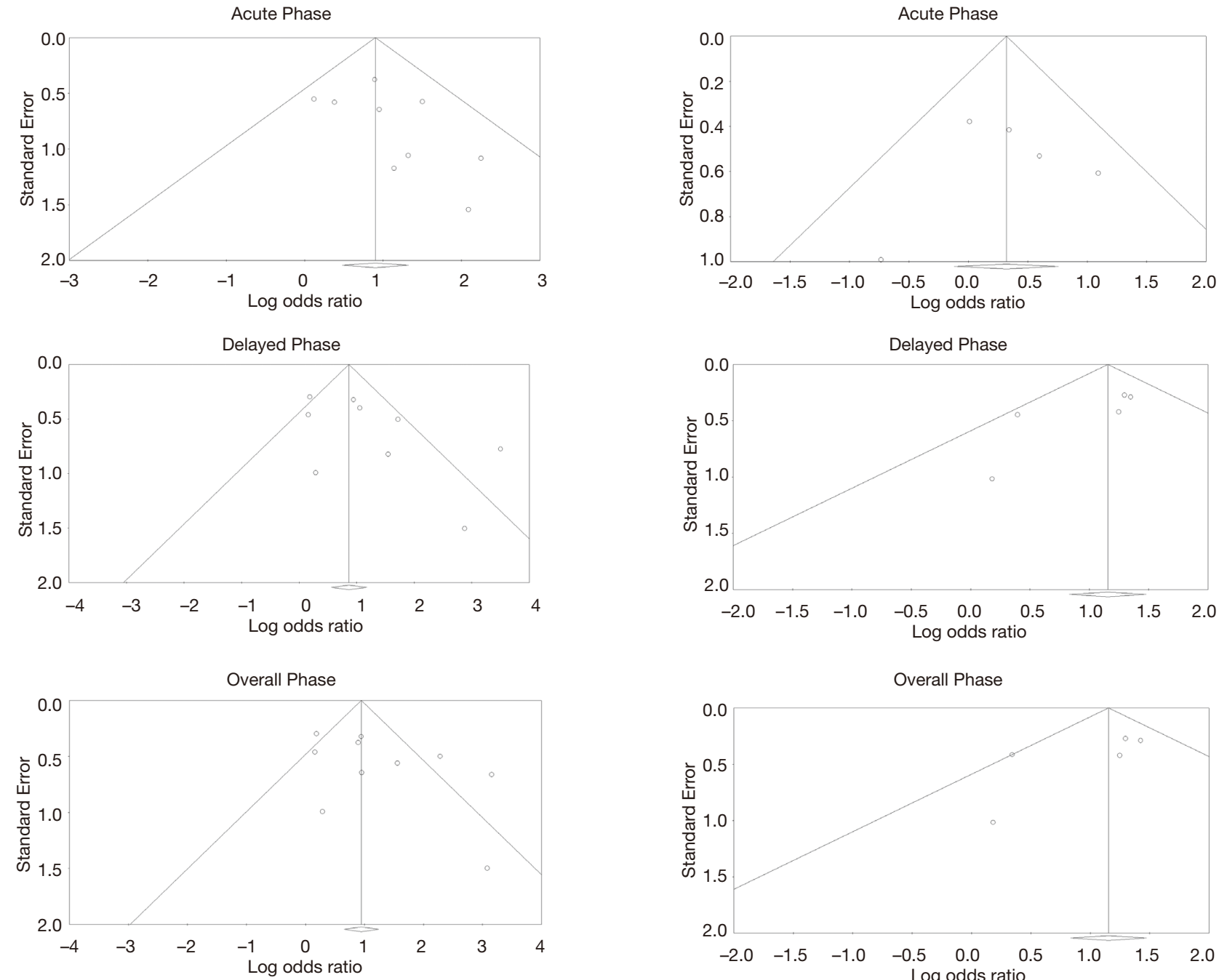

Figure 3 Assessment of publication bias for studies reporting on the efficacy of olanzapine for the prophylaxis of chemotherapyinduced emesis.

\section{Acknowledgments}

Dr. Carlo DeAngelis is the senior author of this project.

Funding: None.

\section{Footnote}

Reporting Checklist: The authors have completed the PRISMA reporting checklist. Available at http://dx.doi. org/10.21037/apm-20-1462

Conflicts of Interest: All authors have completed the ICMJE uniform disclosure form (available at http://

dx.doi.org/10.21037/apm-20-1462). CBS II serves as an unpaid Editor-in-Chief of Annals of Palliative Medicine and reports honorarium from Varian Medical Systems. ML reports consulting fees from Ferring, Abbvie, Sanofi, and AstraZeneca in the past 10 years outside the submitted work. The other authors have no conflicts of interest to declare.

Ethical Statement: The authors are accountable for all aspects of the work in ensuring that questions related to the accuracy or integrity of any part of the work are appropriately investigated and resolved. 
Open Access Statement: This is an Open Access article distributed in accordance with the Creative Commons Attribution-NonCommercial-NoDerivs 4.0 International License (CC BY-NC-ND 4.0), which permits the noncommercial replication and distribution of the article with the strict proviso that no changes or edits are made and the original work is properly cited (including links to both the formal publication through the relevant DOI and the license). See: https://creativecommons.org/licenses/by-nc-nd/4.0/.

\section{References}

1. Chow R, Valdez C, Chow N, et al. Oral cannabinoid for the prophylaxis of chemotherapy-induced nausea and vomiting - a systematic review and meta-analysis. Support Care Cancer 2020;28:2095-103.

2. Osoba D, Zee B, Warr D, et al. Effect of postchemotherapy nausea and vomiting on health-related quality of life. Supportive Care in Cancer 1997;5:307-13.

3. Sankhala KK, Pandya DM, Sarantopoulos J, et al. Prevention of chemotherapy-induced nausea and vomiting: a focus on aprepitant. Expert Opin Drug Metab Toxicol 2009;5:1607-14.

4. Chow R, Tsao M, Chiu L, et al. Efficacy of the combination neurokinin-1 receptor antagonist, palonosetron, and dexamethasone compared to others for the prophylaxis of chemotherapy-induced nausea and vomiting: a systematic review and meta-analysis of randomized controlled trials. Ann Palliat Med 2018;7:221-33.

5. Chasen MR, Rapoport BL. Rolapitant for the treatment of chemotherapy-induced nausea and vomiting: a review of the clinical evidence. Future Oncol 2016;12:763-78.

6. Vrabel M. Is ondansetron more effective than granisetron for chemotherapy-induced nanusea and vomiting? A review of comparative trials. Clin J Oncol Nurs 2007;11:809-13.

7. Chow R, Warr DG, Navari RM, et al. Should palonosetron be a preferred 5-HT3 receptor antagonist for chemotherapy-induced nausea and vomiting? An updated systematic review and meta-analysis. Support Care Cancer 2018;26:2519-49.

8. Srivastava M, Brito-Dellan N, Davis MP, et al. Olanzapine as an antiemetic in refractory nausea and vomiting in advanced cancer. J Pain Symptom Manage 2003;25:578-82.

9. Chow R, Chiu L, Navari R, et al. Efficacy and safety of olanzapine for the prophylaxis of chemotherapy-induced nausea and vomiting (CINV) as reported in phase I and
II studies: a systematic review. Support Care Cancer 2016;24:1001-8.

10. Chiu L, Chow R, Popovic M, et al. Efficacy of olanzapine for the prophylaxis and rescue of chemotherapy-induced nausea and vomiting (CINV): a systematic review and meta-analysis. Support Care Cancer 2016;24:2381-92.

11. Hesketh PJ, Kris MG, Basch E, et al. Antiemetics: American Society of Clinical Oncology clinical practice guideline update. J Clin Oncol 2017;35:3240-61.

12. Berger MJ, Ettinger DS, Aston J, et al. NCCN guidelines insights: antiemesis, version 2.2017. J Natl Compr Canc Netw 2017;15:883-93.

13. Ithimakin $\mathrm{S}$, Theeratrakul $\mathrm{P}$, Laocharoenkiat A, et al. Randomized, double-blind, placebo-controlled study of aprepitant versus two dosages of olanzapine with ondansetron plus dexamethasone for prevention of chemotherapy-induced nausea and vomiting in patients receiving high-emetogenic chemotherapy. Support Care Cancer 2020;28:5335-42.

14. Vimolchalao V, Sakdejayont S, Wongchanapai P, et al. The efficacy and safety of the addition of olanzapine to ondansetron and dexamethasone for prevention of chemotherapy-induced nausea and vomiting in patients receiving highly emetogenic chemotherapy. Int J Clin Oncol 2020;25:396-402.

15. Yeo W, Lau TKH, Li L, et al. A randomized study of olanzapine-containing versus standard antiemetic regimens for the prevention of chemotherapy-induced nausea and vomiting in Chinese breast cancer patients. Breast 2020;50:30-8.

16. Chow R, Aapro M, Navari RM, et al. Do we still need to study palonosetron for chemotherapy-induced nausea and vomiting? A cumulative meta-analysis. Crit Rev Oncol Hematol 2019;142:164-86.

17. Tan L, Liu J, Liu X, et al. Clinical research of olanzapine for prevention of chemotherapy-induced nausea and vomiting. J Exp Clin Cancer Res 2009;28:131.

18. Shumway NM, Terrazzino SE, Jones CB. A randomized pilot study comparing aprepitant to olanzapine for treatment of chemotherapy-induced nausea and vomiting. J Clin Oncol 2009;27:516.

19. Navari RM, Gray SE, Kerr AC. Olanzapine versus aprepitant for the prevention of chemotherapy-induced nausea and vomiting: a randomized phase III trial. J Support Oncol 2011;9:188-95.

20. Mao WK, Peng L. Clinical observation of olanzapine combined with granisetron and hexadecadrol prevent nausea vomit induced by chemoradiotherapy. Chinese 
Journal of Medicine Guide 2011;13:452-4.

21. Wang X, Wang L. Effectiveness of olanzapine in prevention of chemotherapy induced nausea and vomiting. Chinese Journal of Clinical (Electron Ed) 2012;6:7406-7.

22. Lu YL, Liu W, Du YJ, et al. Antiemetic effect of low dose olanzapine in solid tumor chemotherapy. Chinese Journal of Cancer Prevention and Treatment 2013;20:544-54.

23. Mizukami N, Yamauchi M, Koike K, et al. Olanzapine for the prevention of chemotherapy-induced nausea and vomiting in patients receiving highly or moderately emetogenic chemotherapy: a randomized double-blind, placebo-controlled study. J Pain Symptom Manage 2014;47:542-50.

Cite this article as: Chiu L, Chow R, DeAngelis C, Lock M, Simone CB 2nd. Secondary and cumulative meta-analysis of olanzapine for antiemetic prophylaxis for chemotherapyinduced nausea and vomiting: do we still need to study its effectiveness? Ann Palliat Med 2021;10(3):2540-2547. doi: 10.21037/ apm-20-1462
24. Navari RM, Nagy CK. Olanzapine versus fosaprepitant for the prevention of nausea and vomiting in patients receiving concurrent chemo-radiation treatment. J Clin Oncol 2015;15:9504.

25. Mukhopadhyay S, Kwartra G, Jeyaraj P, et al. Role of olanzapine in chemotherapy-induced nausea and vomiting on platinum-based chemotherapy patients: a randomized controlled study. Support Care Cancer 2017;25:145-54.

26. Wang X, Wang L, Wang H, et al. Effectiveness of olanzapine combined with ondansetron in prevention of chemotherapy-induced nausea and vomiting of non-small cell lung cancer. Cell Biochem Biophys 2015;72:471-3. 


\section{Appendix 1 Study proposal}

Olanzapine for antiemetic prophylaxis for chemotherapy induced nausea and vomiting-do we still need to study its effectiveness? A cumulative meta-analysis

\section{Introduction}

Chemotherapy-induced nausea and vomiting (CINV) is a common side-effect related to cancer treatment that has a detrimental effect on quality of life and may lead to dose reductions and/or noncompliance with treatment $(27,28)$. Since the 1970s, many antiemetics have been designed to target pathways involved in CINV. In 2014, olanzapine, an atypical antipsychotic agent, was incorporated into the National Comprehensive Cancer Network (NCCN) antiemetic guidelines, as phase 2 studies of olanzapine, in combination with a 5-HT3-receptor antagonist and dexamethasone, found the agent to be effective at controlling both acute and delayed chemotherapy-induced emesis in patients who are being treated with highly or moderately emetogenic drugs (27).

Since then, olanzapine-containing antiemetic regimens have been compared extensively to other antiemetics regimens without olanzapine, with respect to efficacy and safety, including several systematic reviews and meta-analysis by our group and others (10,29-33). As with all systematic reviews, there exists the possibility of publication bias, which was not assessed in the prior systematic reviews. In addition, consistent with the volume of literature on this topic, multiple new RCTs have been conducted in more recent years, spurring more meta-analyses that may not change the overall conclusions on the efficacy of olanzapine in the CINV setting.

Given the significant resources required to conduct further RCTs, and the robust literature that now exists on olanzapine in the CINV setting, it is important to elucidate whether further studies are needed. The effect of the latest RCTs on the literature's summary statistics can be understood using a cumulative meta-analysis. This statistical technique computes the summary effect size each time a study is published, and subsequently compares the new to the previous effect size. Such comparisons facilitate an appreciation of scenarios in which the summary effect sizes shifts in point estimate and narrows in CI. When a CI is relatively narrow and little adjustments in effect size are noted with the inclusion of new studies, one may postulate that future studies will have little impact on the literature's summary statistic and, therefore, future studies are not needed.

The primary aim of this study is to conduct a cumulative meta-analysis on the efficacy of olanzapine on chemotherapyinduced nausea and emesis to determine whether further trials could lead to different conclusions in future meta-analyses. A secondary aim was to assess for publication biases.

\section{Methods}

We will conduct a secondary data analysis of the previously-published systematic review and meta-analysis published in 2016 (10). That review has been cited by the 2017 American Society of Clinical Oncology's antiemetic guideline to support their new recommendation of olanzapine for the prophylaxis of CINV for patients receiving highly-emetogenic chemotherapy (11). The methodology for study eligibility and data extraction was previously described (10). Briefly, ten RCTs were included, and the meta-analysis reported olanzapine to be more efficacious than other standard antiemetics for both the prophylaxis and rescue of CINV, with respect to the endpoints of nausea control and emesis control.

A Mantel-Haenszel random-effects analysis model will be used to compute cumulative RR and accompanying $95 \%$ CIs. Funnel plots will be generated to qualitatively assess for publication bias. All analyses will be conducted using Comprehensive Meta-Analysis (Version 3) by Biostat.

\section{References}

27. Navari RM. Olanzapine for the prevention and treatment of chronic nausea and chemotherapy-induced nausea and vomiting. Eur J Pharmacol 2014;722:180-6. 
28. Navari RM, Aapro M. Antiemetic Prophylaxis for Chemotherapy-Induced Nausea and Vomiting. N Engl J Med 2016;374:1356-67.

29. Yang T, Liu Q, Lu M, et al. Efficacy of olanzapine for the prophylaxis of chemotherapy-induced nausea and vomiting: a metaanalysis. Br J Clin Pharmacol 2017;83:1369-79.

30. Yoodee J, Permsuwan U, Nimworapan M. Efficacy and safety of olanzapine for the prevention of chemotherapy-induced nausea and vomiting: A systematic review and meta-analysis. Crit Rev Oncol Hematol 2017;112:113-25.

31. Kumar R, Singh N, Thekkekara RJ, et al. Efficacy of olanzapine for prevention of chemotherapy-induced nausea and vomiting: A systematic review and meta-analysis. J Clin Oncol 2017;35:e21692.

32. Sutherland A, Naessens K, Plugge E, et al. Olanzapine for the prevention and treatment of cancer-related nausea and vomiting in adults. Cochrane Database Syst Rev 2018;9:CD012555.

33. Chelkeba L, Gidey K, Mamo A, et al. Olanzapine for chemotherapy-induced nausea and vomiting: systematic review and metaanalysis. Pharm Pract (Granada) 2017;15:877.

\begin{tabular}{lcccrrr} 
Study name & & \multicolumn{3}{c}{ Cumulative statistics } & \\
\cline { 3 - 6 } & & Point & $\begin{array}{c}\text { Lower } \\
\text { limit }\end{array}$ & $\begin{array}{c}\text { Upper } \\
\text { limit }\end{array}$ & Z-Value & p-Value \\
Navari et al, 2009 & 2.349 & 1.488 & 3.708 & 3.664 & 0.000 \\
Navari et al, 2010 & 2.011 & 1.488 & 2.717 & 4.550 & 0.000 \\
Navari et al, 2013 2.087 & 1.627 & 2.677 & 5.795 & 0.000 \\
& 2.087 & 1.627 & 2.677 & 5.795 & 0.000
\end{tabular}

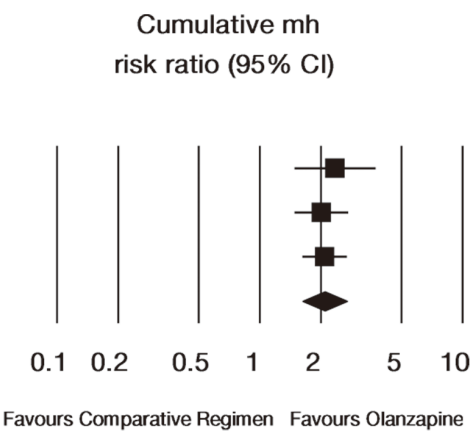

Figure S1 Cumulative efficacy of olanzapine for the rescue of breakthrough chemotherapy-induced emesis.

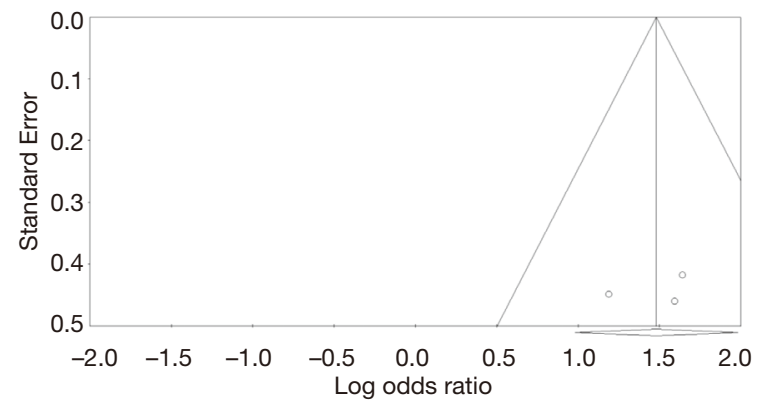

Figure S2 Assessment of publication bias for studies reporting on the efficacy of olanzapine for the rescue of breakthrough chemotherapyinduced emesis. 